\title{
Article \\ Biosynthesis of Polyhydroxyalkanoate Terpolymer from Methanol via the Reverse $\beta$-Oxidation Pathway in the Presence of Lanthanide
}

\author{
Izumi Orita, Gento Unno, Risa Kato and Toshiaki Fukui * $\mathbb{D}$
}

check for updates

Citation: Orita, I.; Unno, G.; Kato,

R.; Fukui, T. Biosynthesis of

Polyhydroxyalkanoate Terpolymer from Methanol via the Reverse

$\beta$-Oxidation Pathway in the Presence

of Lanthanide. Microorganisms 2022

10, 184. https://doi.org/10.3390/

microorganisms10010184

Academic Editor: Akio Tani

Received: 29 October 2021

Accepted: 10 January 2022

Published: 15 January 2022

Corrected: 28 February 2022

Publisher's Note: MDPI stays neutral with regard to jurisdictional claims in published maps and institutional affiliations.

Copyright: (C) 2022 by the authors. Licensee MDPI, Basel, Switzerland. This article is an open access article distributed under the terms and conditions of the Creative Commons Attribution (CC BY) license (https:// creativecommons.org/licenses/by/ $4.0 /)$.
School of Life Science and Technology, Tokyo Institute of Technology, 4259 Nagatsuta, Midori-ku, Yokohama 226-8501, Japan; orita.i.aa@m.titech.ac.jp (I.O.); gento910@gmail.com (G.U.); kato.r.ac@m.titech.ac.jp (R.K.)

* Correspondence: tfukui@bio.titech.ac.jp; Tel.: +81-45-924-5766

\begin{abstract}
Methylorubrum extorquens AM1 is the attractive platform for the production of value-added products from methanol. We previously demonstrated that M. extorquens equipped with PHA synthase with broad substrate specificity synthesized polyhydroxyalkanoates (PHAs) composed of (R)-3hydroxybutyrate and small fraction of $(R)$-3-hydroxyvalerate $(3 \mathrm{HV})$ and $(R)$-3-hydroxyhexanoate (3HHx) units on methanol. This study further engineered M. extorquens for biosynthesis of PHAs with higher $3 \mathrm{HV}$ and $3 \mathrm{HHx}$ composition focusing on the EMC pathway involved in $\mathrm{C}_{1}$ assimilation. The introduction of ethylmalonyl-CoA decarboxylase, catalyzing a backward reaction in the EMC pathway, aiming to increase intracellular propionyl/butyryl-CoA precursors did not affect PHA composition. Reverse $\beta$-oxidation pathway and subsequent $(R)$-specific hydration of 2-enoyl-CoA were then enhanced by heterologous expression of four genes derived from Ralstonia eutropha for the conversion of propionyl/butyryl-CoAs to the corresponding (R)-3-hydroxyacyl-CoA monomers. The resulting strains produced $\mathrm{PHAs}$ with higher $3 \mathrm{HV}$ and $3 \mathrm{HHx}$ compositions, while the methylotrophic growth was severely impaired. This growth impairment was interestingly restored by the addition of $\mathrm{La}^{3+}$ without a negative impact on PHA biosynthesis, suggesting the activation of the EMC pathway by $\mathrm{La}^{3+}$. The engineered M. extorquens synthesized PHA terpolymer composed of $5.4 \mathrm{~mol} \% 3 \mathrm{HV}$ and $0.9 \%$ of $3 \mathrm{HHx}$ with $41 \%$ content from methanol as a sole carbon source in the presence of $\mathrm{La}^{3+}$.
\end{abstract}

Keywords: polyhydroxyalkanoates; methanol; methylotroph; lanthanide; methylotrophy

\section{Introduction}

Plastic pollution in marine environments is now being recognized as a serious global threat [1-3]. It is estimated that microplastics formed from plastic waste will stay in natural environments for hundreds of years due to low degradability of petroleum-based polymers. Polyhydroxyalkanoates (PHAs), which are natural polyesters accumulated within various kinds of microbial cells as a carbon and energy storage, are eco-friendly alternatives to the usual plastics because they show biodegradable properties not only in soil and compost but also in fresh water and sea water. Meanwhile, methanol has received increasing attention as a promising feedstock for the bioindustry based on its sustainability and handleability. Renewable methanol produced from sustainable biomass or $\mathrm{CO}_{2}$ and green hydrogen should offer future development of a methanol-based bioeconomy [4]. Hence, PHA production from methanol feedstock has the potential to establish a sustainable plastic industry.

Methylotrophs, capable of growing on reduced $C_{1}$ compounds such as methanol and methylamine as a sole carbon and energy source, are powerful platforms for the establishment of the methanol-based bioeconomy. Methylorubrum extorquens (formerly Methylobacterium extorquens) AM1 is a model methylotroph for understanding methylotrophy and producing value-added products from methanol. The first step of methanol metabolism 
in this methylotrophic bacterium is oxidation to formaldehyde catalyzed by methanol dehydrogenase (MDH). M. extorquens possesses two distinct types of pyrroloquinoline quinone (PQQ)-dependent $\mathrm{MDH}$, which are $\mathrm{Ca}^{2+}$-dependent $\mathrm{MxaF}$ and lanthanide (Ln)dependent XoxF1 and XoxF2. Formaldehyde is then oxidized to formate, which is the major branching node between the catabolic oxidation and anabolic metabolisms. Formate is further oxidized to $\mathrm{CO}_{2}$ by formate dehydrogenase, or bound to tetrahydrofolate $\left(\mathrm{H}_{4} \mathrm{~F}\right)$ to form methylene $\mathrm{H}_{4} \mathrm{~F}$, in which methanol-derived carbon is used to convert glycine to serine in the serine cycle for carbon assimilation [5]. M. extorquens AM1 lacking isocitrate lyase utilizes the ethylmalonyl-CoA (EMC) pathway for the regeneration of glyoxylate, a precursor of glycine, to maintain the serine cycle.

M. extorquens has been studied well as the producer of single cell proteins as well as several bulk and fine chemicals from methanol [6]. One of the bulk chemicals produced by this bacterium is PHA. The first two steps of the EMC pathway, condensation of two molecules of acetyl-CoA by $\beta$-ketothiolase (PhaA) and reduction of acetoacetyl-CoA to $(R)$-3-hydroxybutyryl-CoA (3HB-CoA) by NADPH-dependent acetyl-CoA reductase (PhaB), are shared with the PHA synthesis pathway. The resulting $(R)-3 \mathrm{HB}-\mathrm{CoA}$ was dehydrated to crotonyl-CoA for further conversion through the EMC pathway, or polymerized to poly $((R)-3$-hydroxybutyrate) $(\mathrm{P}(3 \mathrm{HB}))$ by $\mathrm{PHA}$ synthase $(\mathrm{PhaC}) . \mathrm{P}(3 \mathrm{HB})$ is the most abundant PHA produced by a wide variety of microorganisms in nature, but this homopolyester is unsuitable for applications because of its stiff and brittle properties due to the high crystallinity. It is well known that copolymerization of the $3 \mathrm{HB}$ unit with other monomer units such as $\mathrm{C}_{5}$-unit $(R)$-3-hydroxyvalerate $(3 \mathrm{HV}), \mathrm{C}_{6}$-unit $(R)$-3hydroxyhexanoate (3HHx), 4-hyroxybutyrate, and so on, often leads to alternative physical and mechanical properties. Although it had been thought that only $\mathrm{P}(3 \mathrm{HB})$ was accumulated during methylotrophic growth of $M$. extorquens AM1, we previously revealed that this bacterium is able to synthesize PHA copolymer containing $3 \mathrm{HV}$ from methanol under cobalt-deficient conditions [7]. Furthermore, the recombinant strain named $A M 1 C_{A c}$, in which original PHA synthase gene $\left(p h a C_{M e}\right)$ was replaced by $p h a C_{A c}$ encoding the homolog with broad substrate specificity from Aeromonas caviae, accumulated PHA terpolymer composed of $3 \mathrm{HB}, 3 \mathrm{HV}$, and additional $3 \mathrm{HHx}$, whereas the $3 \mathrm{HV}$ and $3 \mathrm{HHx}$ compositions in this terpolymer $\mathrm{P}(3 \mathrm{HB}-\mathrm{co}-3 \mathrm{HV}-\mathrm{co}-3 \mathrm{HHx})$ were low (0.71 and $0.28 \mathrm{~mol} \%$, respectively) [7].

Recently, an artificial pathway for biosynthesis of $\mathrm{P}(3 \mathrm{HB}-\mathrm{co}-3 \mathrm{HHx})$ from sugars has been constructed in the representative PHA producer Ralstonia eutropha (Cupriavidus necator) $[8,9]$ In this pathway, the $3 \mathrm{HHx}$ monomer was synthesized through the condensation of butyryl-CoA with acetyl-CoA, where butyryl-CoA is provided from crotonyl-CoA by two ways. One is direct formation by reductase activity of crotonyl-CoA carboxylase/reductase (Ccr) derived from $M$. extorquens and another is two step reactions proceeded via reductive carboxylation of crotonyl-CoA and decarboxylation of the resulting ethylmalonyl-CoA catalyzed by the bifunctional Ccr and ethylmalonyl-CoA decarboxylase (Emd) derived from mouse, respectively. As Ccr is one of the key enzymes in the EMC pathway, butyryl-CoA is potentially synthesized in $M$. extorquens under the methylotrophic conditions. Indeed, a small amount of butyryl-CoA was detected in the cell extracts of M. extorquens AM1 grown on ethylamine $[10,11]$ However, the reductase activity of Cor from the strain AM1 was estimated to be much lower than the reductive carboxylase activity [8] as seen for Ccr from Rhodobacter sphaeroides [12,13].

In this study, we engineered M. extorquens AM1 to increase the supply of 3HV and $3 \mathrm{HHx}$ monomer units focusing on the presence of the precursors, propionyl-CoA and butyryl-CoA, in the EMC pathway. The introduction of Emd in combination with the enhancement of reverse $\beta$-oxidation (RBO) pathway achieved biosynthesis of PHA with both higher content and compositions of $3 \mathrm{HV}$ and $3 \mathrm{HHx}$, whereas the modification in the EMC pathway was accompanied with severe impairment in methylotrophic growth. Interestingly, the impaired methylotrophic growth was restored by the addition of $\mathrm{La}^{3+}$ with maintaining the higher PHA content and $\mathrm{C}_{5} / \mathrm{C}_{6}$-monomer composition. This study 
proposes the potential of lanthanide for the application of the EMC pathway for the production of value-added products from methanol.

\section{Materials and Methods}

\subsection{Bacterial Strains and Culture Condition}

Bacterial strains used in this study are listed in Table 1. M. extorquens strains were cultivated at $30{ }^{\circ} \mathrm{C}$ in a hypho minimal medium [14] within a $500 \mathrm{~mL}$ flask with reciprocal shaking (115 strokes/min). Trace element solution containing EDTA (12.7 $\mathrm{g}$ of $\mathrm{Na}_{2}$ EDTA $2 \mathrm{H}_{2} \mathrm{O}, 4.4 \mathrm{~g}$ of $\mathrm{ZnSO}_{4} 7 \mathrm{H}_{2} \mathrm{O}, 1.47 \mathrm{~g}$ of $\mathrm{CaCl}_{2} 2 \mathrm{H}_{2} \mathrm{O}, 1.01 \mathrm{~g}$ of $\mathrm{MnCl}_{2} 4 \mathrm{H}_{2} \mathrm{O}, 0.998 \mathrm{~g}$ of $\mathrm{FeSO}_{4}$ $7 \mathrm{H}_{2} \mathrm{O}, 0.22 \mathrm{~g}$ of $\left(\mathrm{NH}_{4}\right)_{6} \mathrm{Mo}_{7} \mathrm{O}_{24} 4 \mathrm{H}_{2} \mathrm{O}, 0.314 \mathrm{~g}$ of $\mathrm{CuSO}_{4} 5 \mathrm{H}_{2} \mathrm{O}$, and $0.322 \mathrm{~g}$ of $\mathrm{CoCl}_{2} 6 \mathrm{H}_{2} \mathrm{O}$ in $1 \mathrm{~L}$ deionized water) was added into the medium $(1 \mathrm{~mL} / 1 \mathrm{~L}$ medium) except for some cases investigating the effects of metal ions. The standard cultivation of $M$. extorquens on methanol was carried out as described in the previous report [7]. Briefly, the cells pre-cultivated in a $50 \mathrm{~mL}$ hypho minimal medium containing $20 \mathrm{mM}$ succinate for 2 days were inoculated into the $100 \mathrm{~mL}$ hypho minimal medium containing $125 \mathrm{mM}$ methanol at the initial $\mathrm{OD}_{600}$ was 0.1. E. coli strains were grown at $37^{\circ} \mathrm{C}$ using a Lysogeny broth (LB) medium for general gene manipulation. Kanamycin $(100 \mathrm{mg} / \mathrm{L})$ or ampicillin $(50 \mathrm{mg} / \mathrm{L})$ was added to the medium for the strains harboring the vector. The cell growth was monitored with optical density (OD) at $600 \mathrm{~nm}$ using a JASCO V-550 spectrophotometer (Jasco, Tokyo, Japan).

Table 1. Strains and plasmids used in this study.

\begin{tabular}{|c|c|c|}
\hline Strains or Plasmids & Relevant Characteristics & Source or Reference \\
\hline \multicolumn{3}{|l|}{ Escherichia coli } \\
\hline $\mathrm{DH} 5 \alpha$ & $\begin{array}{c}\text { deoR, endA1, gyrA96, hsdR17 }\left(\mathrm{r}_{\mathrm{K}}^{-} \mathrm{m}_{\mathrm{K}}^{+}\right), \operatorname{rec} A 1, \\
\text { relA1, supE44, thi-l, } \Delta(\operatorname{lacZ} Y A-\arg F V 169) \\
\varphi 80 \text { lacZ } \Delta \mathrm{M} 15, \mathrm{~F}^{-}, \lambda^{-}\end{array}$ & Clontech (Palo Alto, CA) \\
\hline \multicolumn{3}{|l|}{ Methylorubrum extorquens } \\
\hline AM1 & Wild type & \\
\hline $\mathrm{AM} 1 \mathrm{C}_{\mathrm{NSDG}}$ & AM1 derivative; $p h a C_{M e}:: p h a C_{N S D G}$ & This study \\
\hline AM1C NSDG_emd $_{2}$ & 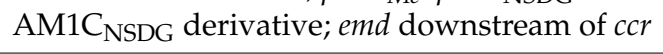 & This study \\
\hline \multicolumn{3}{|l|}{ Plasmids } \\
\hline pK18mobsacB & pMB1 ori, RP4 mob, modified sacB, lacZa, $\mathrm{Kan}^{\mathrm{r}}$ & [15] \\
\hline pK18_phaC ${ }_{\text {NSDG }}$ & pK 18 mobsacB carrying phaC ${ }_{\mathrm{NSDG}}$ & This study \\
\hline pTAKN-2-emdMm & pTAKN-2 cloning vector carrying $e m d_{M m}$ & [8] \\
\hline pK18_emd & pK18mobsacB carrying $e m d_{M m}$ & This study \\
\hline $\mathrm{pCM} 80 \mathrm{Km}$ & pCM80 derivative; $\operatorname{Tc}^{r}:: \operatorname{Kan}^{r}$ & {$[7,16]$} \\
\hline pCM80Km_emd & pCM $80 \mathrm{Km}$ carrying $\mathrm{emd}_{\mathrm{Mm}}$ & This study \\
\hline pCM80Km_emdbktB & pCM $80 \mathrm{Km}$ carrying $e m d_{M m}-b k t B_{R e}$ & This study \\
\hline pUC118 & $A_{m p}{ }^{r}$ general cloning vector & Takara Bio (Ohtsu, Japan) \\
\hline pUC-hadcrt2 & pUC118 carrying had $_{R e^{-c r t} 2_{R e}}$ & This study \\
\hline pCM80Km-ehcjb & 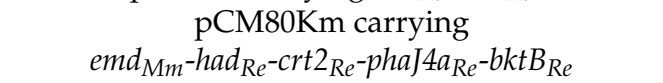 & This study \\
\hline pCM80Km-hcjb & $\begin{array}{c}\text { pCM80Km carrying } \\
h a d_{R e^{-c r t 2}} e_{e}-p h a J 4 a_{R e}-b k t B_{R e}\end{array}$ & This study \\
\hline pCM80PphaA-hcjb & pCM80Km-hcjb derivative; $P_{m x a F}:: P_{\text {phaA }}$ & This study \\
\hline
\end{tabular}

\subsection{Construction of Host Strains}

General genetic manipulations were performed according to the standard procedures. Primers used in this study are listed in the Supplementary Table S1.

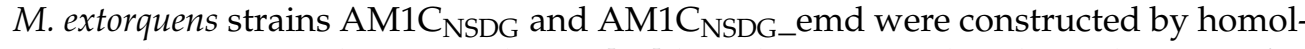
ogous recombination with pK18mobsacB [15]-based vectors. The plasmid vectors for homologous recombination were constructed as follows. A DNA fragment containing phaC with its flanking regions (approximately 1-kbp each) was amplified from $M$. extorquens

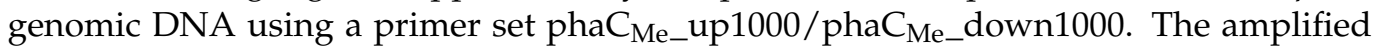
fragment was digested by EcoRI and inserted into pK18mobsacB at the corresponding site. 
Inverse PCR was carried out using the resulting plasmid as a template and a primer set InvphaC_N/InvphaC-C to amplify the flanking regions of $p h a C$ along with pK18mobsacB backbone. The amplified fragment was ligated with a DNA fragment of $p h a C_{N S D G}$ amplified using pTA2_NSDG [17] and $\mathrm{phaC}_{\mathrm{Ac} \_} \mathrm{N} / \mathrm{phaC} \mathrm{Ac}_{\mathrm{A}-\mathrm{C}}$ as a template and a primer set, respectively. The resulting plasmid was designated as pK18_phaC NSDG. $_{\text {. }}$.

An approximately 2-kbp fragment containing the upstream and downstream regions (approximately 1-kbp each) flanking to the stop codon of $c c r$ was amplified from M. extorquens genomic DNA using a primer set $\mathrm{ccr}_{\mathrm{Me}} \mathrm{C}-\mathrm{up} 1000 / \mathrm{ccr}_{\mathrm{Me}} \mathrm{C}-\mathrm{down} 1000$. A 5'phosphorylated PCR product was inserted into $\mathrm{pK} 18 \mathrm{mobsacB}$ at the SmaI site. The resulting plasmid was used for inverse PCR as a template with a primer set Ccr $_{\mathrm{Me}} \mathrm{C}$-Inv1/ $\mathrm{Crr}_{\mathrm{Me}} \mathrm{C}$ Inv2. The amplified fragment was digested by BamHI, and then ligated with an $e m d_{M m}$ fragment excised by digestion with BamHI and EcoRV from pTAKN-2-emdMm harboring a synthetic gene encoding mouse ethylmalonyl-CoA decarboxylase ECHDC1 with codons optimized for R. eutropha [8]. The resulting plasmid was designated as pK18_emd.

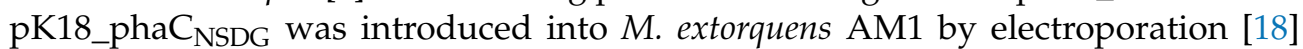
using a Gene Pulser Xcell ${ }^{\mathrm{TM}}$ Electroporation System (Bio-Rad), and the transformant AM1 $C_{\text {NSDG }}$ was obtained by a pop-in/pop-out recombination as described previously [7].

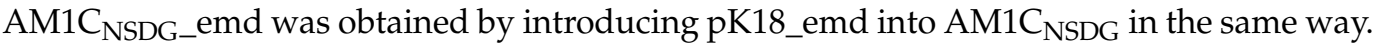

\subsection{Construction of Expression Plasmids}

Several expression vectors for $M$. extorquens strains were constructed using pCM80Km harboring a strong promoter $P_{m x a F}[7,16]$. An $e m d_{M m}$ fragment was amplified using pTAKN2-emdMm and emd_N/emd_C as a template and a primer set, respectively. The amplified fragment was digested by HindIII and XbaI, followed by ligation into pCM80Km at the corresponding site to obtain pCM80Km_emd.

A $b k t B_{R e}$ fragment was amplified from R. eutropha genomic DNA using a primer set bktB_N/bktB_C, and then digested by BamHI and EcoRI. The digested fragment was inserted into pCM80Km_emd at the corresponding site to obtain pCM80Km_emdbktB.

A tandem of $h a d_{R e}$ (H16_A0602)-crt2 $2_{R e}$ (H16_A3307) genes was prepared by fusion PCR. The $h a d_{R e}$ and $c r t 2_{R e}$ fragments were individually amplified from R. eutropha genomic DNA using A0602-F/A0602-R-Fus and A3307-F-Fus/A3307-R as the primer sets, respectively. The resulting fragments and a primer set A0602-F/A3307-R were used for fusion $\mathrm{PCR}$, and the fused fragment was cloned into pUC118 at the HincII site. The had-crt $2_{R e}$ fragment amplified from the pUC-hadcrt2 with A0602A3307up/A0602A3307down primers and a $p h a J 4 a_{R e}$ fragment amplified from pBPP-J4a [19] with phaJup/phaJdown primers were digested by EcoRI and ligated to each other. The ligation mixture was used as a template for amplification of a had-crt2-pha $4 a_{R e}$ fragment, and the resulting fragment was digested by $\mathrm{XbaI}$ and BamHI, followed by insertion into pCM80Km_emdbktB at the corresponding sites to obtain pCM80Km-ehcjb. pCM80Km-hcjb was prepared by excision of the $\mathrm{emd}_{\mathrm{Mm}}$ region by digestion with $\mathrm{XbaI}$ and HindIII and subsequent blunting and self-ligation.

pCM80PphaA-hcjb was constructed by replacing $P_{m x a F}$ with a promoter region of phaA $\left(P_{\text {phaA }}\right)$ in pCM80Km-hcjb. The $P_{\text {phaA }}$ region was amplified using genomic DNA of $M$. extorquens AM1 and PphaA-FwNheI/PphaA-Rv as a template and primer pair, respectively. Inverse PCR was carried out to obtain a linearized pCM80Km-hcjb lacking $P_{m x a F}$ with primers pCM80-Inv5/A0602-F. These PCR products were digested by NheI and ligated to each other.

\subsection{PHA Analyses and Measurement of Methanol Concentration}

The cells grown to stationary phase were harvested by centrifugation at $8000 \times g$ for $10 \mathrm{~min}$ at $4^{\circ} \mathrm{C}$ and washed with deionized water, followed by lyophilization. The dried cells were then subjected to methanolysis in the presence of $15 \%(v / v)$ sulfuric acid in methanol as described previously $[20,21]$. The reaction mixture was analyzed by gas chromatography using a GC-2014 (Shimadzu, Kyoto, Japan) equipped with an InertCap 1 capillary column ( $30 \mathrm{~m}$ by $0.23 \mathrm{~mm}$; GL Sciences, Tokyo, Japan) and a flame ionization detector. The cellular 
content and composition were calculated using coefficient obtained by measuring standard PHAs under the same condition.

One $\mathrm{mL}$ portion of the culture broth was centrifuged at $17,700 \times \mathrm{g}, 1 \mathrm{~min}$ at $4^{\circ} \mathrm{C}$, and the supernatants were subjected for determination of methanol concentration using GC-2014 equipped with the same column and detector.

\subsection{Methanol Dehydrogenase Assay}

The $M$. extorquens strains were cultivated for $48 \mathrm{~h}$ after inoculation with an initial $\mathrm{OD}_{600} 0.1 \mathrm{in} 100 \mathrm{~mL}$ of hypho medium containing $0.5 \%$ methanol with or without $30 \mathrm{mM}$ of $\mathrm{LaCl}_{3}$. The cells were harvested by centrifugation at $8000 \times \mathrm{g}$ for $10 \mathrm{~min}$ at $4{ }^{\circ} \mathrm{C}$, and then washed with $50 \mathrm{mM}$ Tris- $\mathrm{HCl}$ buffer ( $\mathrm{pH}$ 7.5). The cells resuspended within $20 \mathrm{mM}$ Tris- $\mathrm{HCl}$ buffer ( $\mathrm{pH}$ 7.5) containing $5 \mathrm{mM} \mathrm{MgCl} 2$ and $1 \mathrm{mM}$ DTT were disrupted by a high-pressure cell disruptor (one-shot model) (Constant Systems, Northants, UK) at 20,000 psi. The cell debris was removed by centrifugation at $8000 \times g$ for $30 \mathrm{~min}$ at $4{ }^{\circ} \mathrm{C}$ and the supernatants were used as crude extracts for enzyme assay. Protein concentration was determined by the Bradford method with bovine serum albumin as the standard.

Methanol dehydrogenase (MDH) activity was measured based on the method by Day and Anthony [22] with slight modifications. Briefly, the reaction mixture was composed of $100 \mathrm{mM}$ Tris- $\mathrm{HCl}$ buffer (pH 9.0), $15 \mathrm{mM} \mathrm{NH}_{4} \mathrm{Cl}, 50 \mathrm{mM}$ 2,6-dichloroindophenol (DCIP), $2 \mathrm{mM}$ phenazine methosulfate (PMS), $1 \mathrm{mM} \mathrm{KCN}$, and $10 \mathrm{mM}$ methanol. The appropriate volume of the crude extract was added into the reaction mixture not containing methanol in a cuvette, and pre-incubated for $5 \mathrm{~min}$ at $30^{\circ} \mathrm{C}$ for stabilization. The reaction was initiated by the addition of methanol and the substrate-dependent increase in absorbance at $600 \mathrm{~nm}$ $\left(\varepsilon_{600}=21 \mathrm{mM}^{-1} \mathrm{~cm}^{-1}\right)$ was recorded using JASCO V-550 spectrophotometer.

\section{Results}

\subsection{Introduction of Ethylmalonyl-CoA Decarboxylase into M. extorquens}

We previously demonstrated that $M$. extorquens $A M 1 C_{A c}$ harboring $\mathrm{PhaC}_{A c}$ with broad substrate specificity synthesized $\mathrm{P}(3 \mathrm{HB}-\mathrm{co}-3 \mathrm{HV}-\mathrm{co}-3 \mathrm{HHx})$ terpolymers containing small fractions of $\mathrm{C}_{5}(3 \mathrm{HV})$ and $\mathrm{C}_{6}(3 \mathrm{HHx})$ units from methanol as a sole carbon source, as described above [7]. In this study, the double mutant (N149S/D171G) of $\mathrm{PhaC}_{A c}$, $\mathrm{PhaC}_{\mathrm{NSDG}}$ showing enhanced ability to incorporate the $3 \mathrm{HHx}$ unit [23], was adopted as the polymerizing enzyme in $M$. extorquens (Figure 1A). The resulting strain $\mathrm{AM}_{\mathrm{N}} \mathrm{C}_{\mathrm{NSDG}}$ accumulated $31 \mathrm{wt} \%$ of the PHA terpolymer per dry cell weight (DCW) with $0.5 \mathrm{~mol} \% 3 \mathrm{HV}$ and $0.23 \mathrm{~mol} \% 3 \mathrm{HHx}$ compositions after $72 \mathrm{~h}$ cultivation on methanol, which were similar to the $\mathrm{AM} 1 \mathrm{C}_{\mathrm{Ac}}$ strain [7]. Considering the higher $3 \mathrm{HHx}$ composition in PHA produced by

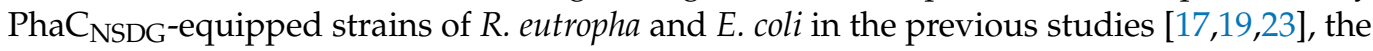

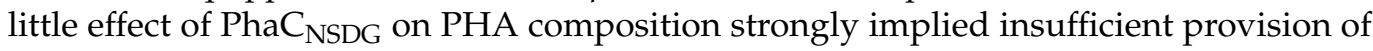
the $3 \mathrm{HV}$ and $3 \mathrm{HHx}$ monomer units from methanol in M. extorquens. The strain AM1 $\mathrm{C}_{\mathrm{NSDG}}$ was used as the host strain for further metabolic engineering.

The $\mathrm{C}_{5}$ and $\mathrm{C}_{6}$ monomers, $3 \mathrm{HV}-\mathrm{CoA}$ and $3 \mathrm{HHx}-\mathrm{CoA}$ respectively, were supposed to be formed from propionyl-CoA and butyryl-CoA in the EMC pathway [7]; the availability of theses precursors for PHA synthesis would affect composition of the accumulated PHA. Emd, firstly identified in mammalian tissues [24], has been reported to show decarboxylation activity towards not only (S)-ethylmalonyl-CoA but also (S)-methylmalonyl-CoA, where the activity to methylmalonyl-CoA was lower than that to ethylmalonyl-CoA [24]. We therefore introduced Emd into M. extorquens AM1 $\mathrm{C}_{\mathrm{NSDG}}$ in anticipation of increasing intracellular concentration of both propionyl-CoA and butyryl-CoA by the backward reaction in the EMC pathway. When $e m d_{M m}$ was introduced by using an expression vector pCM $80 \mathrm{Km}$, the growth of the transformant on methanol was severely impaired. This suggested that the expression of the plasmid-borne $e m d_{M m}$ under the control of strong methanol dehydrogenase promoter $\left(P_{\text {mxaF }}\right)$ was too high to maintain enough turnover of the EMC pathway required for the methylotrophic growth. 

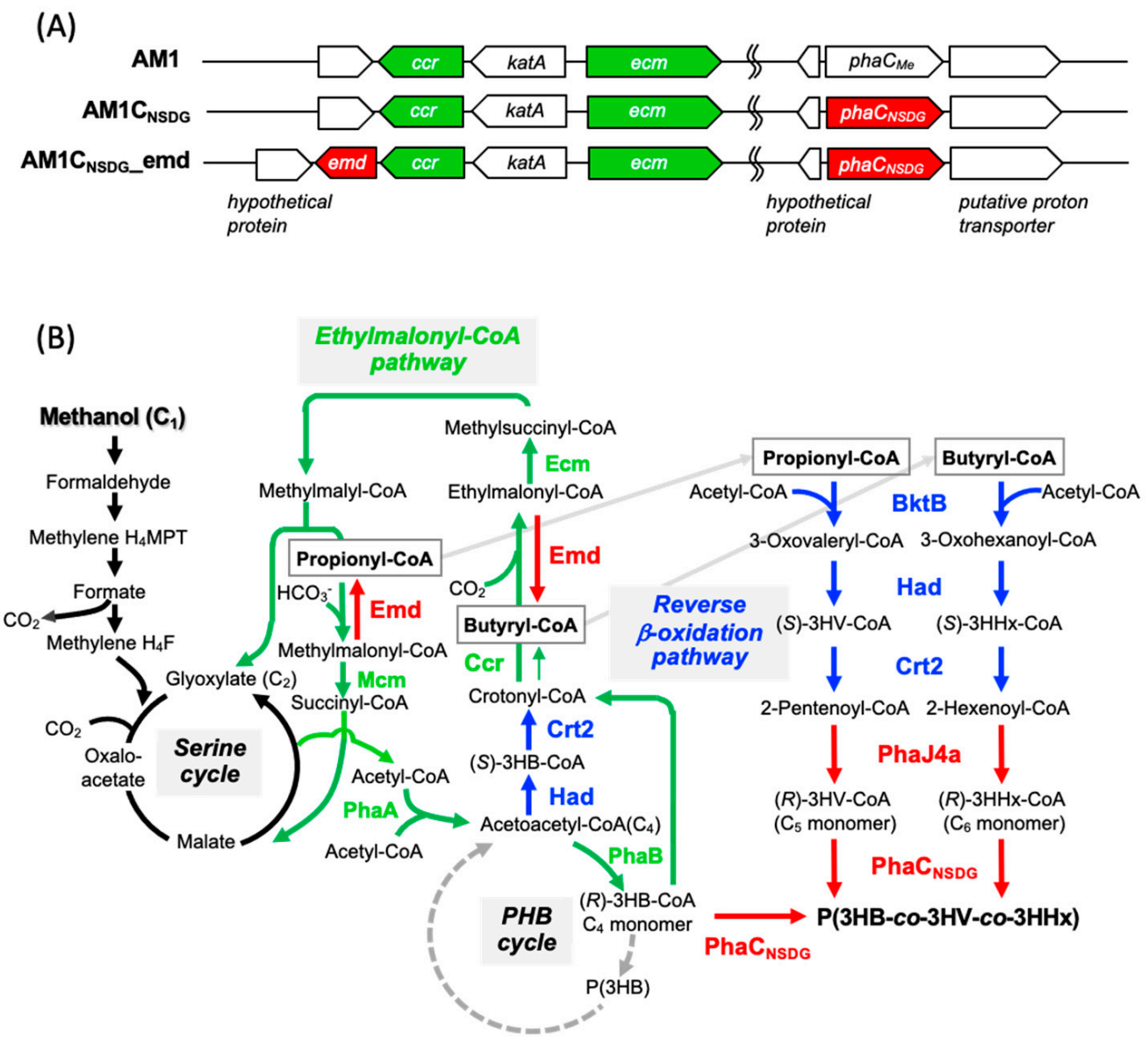

Figure 1. (A) Organization of modified genes on chromosome of M. extorquens AM1 for PHA biosynthesis. (B) Methanol assimilation and $\mathrm{P}(3 \mathrm{HB}-c o-3 \mathrm{HV}-c o-3 \mathrm{HHx})$ biosynthesis pathways in M. extorquens $\mathrm{AM} 1 \mathrm{C}_{\mathrm{NSDG}}$ emd harboring genes for RBO pathway. 2PG, 2-phosphoglycerate; PEP, phosphoenolpyruvate; PhaA, $\beta$-ketothiolase; $\mathrm{PhaB}, \mathrm{NADPH}$-acetoacetyl-CoA reductase; $\mathrm{Ccr}$, crotonylCoA reductase/carboxylase; Ecm, ethylmalonyl-CoA mutase; $\mathrm{Mcm}$, methylmalonyl-CoA mutase, Emd, ethylmalonyl-CoA decarboxylase; PhaC $_{\mathrm{NSDG}}, \mathrm{N} 149 \mathrm{~S} / \mathrm{D} 171 \mathrm{G}$ mutant of PHA synthase from A. caviae; BktB, short-medium-chain-specific $\beta$-ketothiolase; Had, NAD ${ }^{+}-(S)$-3-hydroxyacyl-CoA dehydrogenase; $\mathrm{Crt2}$, (S)-specific enoyl-CoA hydratase (crotonase); PhaJ4a, medium-chain-specific $(R)$-enoyl-CoA hydratase. BktB, Had, Crt2, and PhaJ4a are derived from R. eutropha, and Emd is derived from Mus musculus (codon optimized).

It has been reported that specific activity of Ccr in M. extorquens was moderately high during the methylotrophic growth [25]. $e m d_{M m}$ was therefore inserted at downstream of $\mathrm{ccr}$ on the chromosome of $M$. extorquens $\mathrm{AM} 1 \mathrm{C}_{\mathrm{NSDG}}$ aiming at the moderate expression

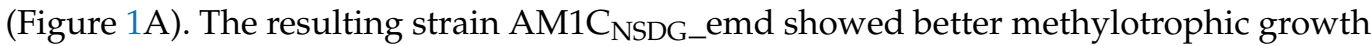
compared to $\mathrm{AM} 1 \mathrm{C}_{\mathrm{NSDG}} / \mathrm{pCM} 80 \mathrm{Km}$-emd, while slight growth retardation was observed on methanol.

The PHA production by the strains $A M 1 C_{\text {NSDG }}$ and $A M 1 C_{\text {NSDG_emd after }} 72 \mathrm{~h}$ cultiva-

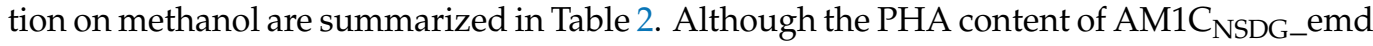
was 1.5-times higher than that of $A M 1 C_{N S D G}$, the decrease in DCW of $A M 1 C_{N S D G}$ emd resulted in lower PHA production $(0.12 \mathrm{~g} / \mathrm{L})$ than that by $\mathrm{AM}_{1} \mathrm{C}_{\mathrm{NSDG}}(0.27 \mathrm{~g} / \mathrm{L})$. The monomer composition of PHAs produced by these strains were very similar to each other. The cultivation on methanol in the medium supplemented with EDTA-free trace element solution was further examined, because we have previously observed that the methylotrophic growth rate of $M$. extorquens AM1 was increased in the absence of EDTA. This was speculated to be due to higher metabolic flux of the EMC pathway attributed to higher activity of two vitamin $\mathrm{B}_{12}$-dependent mutases in the EMC pathway, ethylmalonyl-CoA 
mutase and methylmalonyl-CoA mutase, under high concentration of $\mathrm{Co}^{2+}$ without chelation by EDTA $[7,26]$. Both DCW and PHA production by the strain AM1C ${ }_{\text {NSDG_emd were }}$ restored to comparable level to those of $A M 1 C_{\text {NSDG }}$ in the absence of EDTA, whereas the $3 \mathrm{HV}$ and $3 \mathrm{HHx}$ fractions in the accumulated PHA were slightly reduced (Table 2).

Table 2. $\mathrm{P}(3 \mathrm{HB}-\mathrm{co}-3 \mathrm{HV}-\mathrm{co}-3 \mathrm{HHx})$ biosynthesis by M. extorquens emd-introducing strains from methanol.

\begin{tabular}{|c|c|c|c|c|c|c|c|c|}
\hline \multirow{2}{*}{ Strain } & \multirow{2}{*}{ EDTA } & \multirow{2}{*}{$\begin{array}{l}\text { Dry Cell } \\
\text { Weight } \\
\text { (g/L) }\end{array}$} & \multirow{2}{*}{$\begin{array}{c}\text { PHA } \\
\text { Content } \\
\left(w t^{\circ}\right)\end{array}$} & \multirow{2}{*}{$\begin{array}{l}\text { PHA } \\
(\mathrm{g} / \mathrm{L})\end{array}$} & \multirow{2}{*}{$\begin{array}{c}\text { Residual Cell } \\
\text { Weight } \\
\text { (g/L) }\end{array}$} & \multicolumn{3}{|c|}{$\begin{array}{c}\text { Monomer Composition } \\
(\mathrm{mol} \%)\end{array}$} \\
\hline & & & & & & $3 \mathrm{HB}$ & $3 \mathrm{HV}$ & $3 H H x$ \\
\hline $\mathrm{AM} 1 \mathrm{C}_{\mathrm{NSDG}}$ & & $0.96 \pm 0.11$ & $28.0 \pm 2.6$ & $0.27 \pm 0.02$ & $0.69 \pm 0.10$ & $99.3 \pm 0.1$ & $0.45 \pm 0.09$ & $0.23 \pm 0.02$ \\
\hline AM1C ${ }_{\text {NSDG_emd }}$ & + & $0.28 \pm 0.06$ & $42.5 \pm 8.1$ & $0.11 \pm 0.01$ & $0.16 \pm 0.06$ & $99.3 \pm 0.2$ & $0.39 \pm 0.20$ & $0.33 \pm 0.01$ \\
\hline $\mathrm{AM}_{1 C_{\mathrm{NSDG}}}$ & & $1.11 \pm 0.07$ & $33.1 \pm 1.9$ & $0.37 \pm 0.01$ & $0.74 \pm 0.07$ & $99.6 \pm 0.0$ & $0.18 \pm 0.01$ & $0.18 \pm 0.01$ \\
\hline AM1C ${ }_{\text {NSDG_emd }}$ & - & $1.08 \pm 0.03$ & $23.1 \pm 1.0$ & $0.25 \pm 0.01$ & $0.83 \pm 0.02$ & $96.6 \pm 0.0$ & $0.20 \pm 0.01$ & $0.17 \pm 0.02$ \\
\hline
\end{tabular}

\subsection{Enhancement of the Reverse $\beta$-Oxidation (RBO) Pathway}

Despite the poor growth on methanol caused by Emd $_{M m}$ catalyzing decarboxylation opposite to the usual direction of the EMC pathway, no significant increase in fractions of $3 \mathrm{HV}$ and $3 \mathrm{HHx}$ was observed, suggesting insufficient function of the native pathway for conversion of propionyl/butyryl-CoAs to the corresponding ( $R$ )-3-hydroxyacyl (3HA)-CoA monomers. Recently, we enhanced the RBO pathway responsible for the conversion of butyryl-CoA to (R)-3HHx-CoAs in R. eutropha for biosynthesis of $\mathrm{P}(3 \mathrm{HB}-\mathrm{co}-3 \mathrm{HHx})$ from glucose [9]. In the enhanced $\mathrm{RBO}$ pathway, $\beta$-ketothiolase $\left(\mathrm{BktB}_{R e}\right), \mathrm{NAD}^{+}$-dependent $(S)-3 \mathrm{HA}-\mathrm{CoA}$ dehydrogenase $\left(\mathrm{Had}_{R e}\right)$, and $(S)$-specific enoyl-CoA hydratase (crotonase) $\left(\mathrm{Crt} 2_{R e}\right)$ potentially formed 2-enoyl-CoAs of $\mathrm{C}_{5} / \mathrm{C}_{6}$ from propionyl/butyryl-CoAs and acetyl-CoA via (S)-3HA-CoAs. Then, $(R)$-enoyl-CoA hydratase (PhaJ4a $\mathrm{a}_{R e}$ ) converted 2enoyl-CoAs to (R)-3HA-CoAs. The four enzymes derived from $R$. eutropha, all of which have been demonstrated to show rather broad substrate specificity accepting the medium-chainlength intermediates $[19,27]$, were applied in $M$. extorquens to promote the supply of the $3 \mathrm{HV} / 3 \mathrm{HHx}$-monomer units (Figure 1B). When an artificial cluster of had-crt2-phaJ $4 a-b k t B_{R e}$ flanked to the strong promoter $P_{m x a F}$ was introduced into $M$. extorquens $A M 1 C_{\text {NSDG_emd }}$ by using the plasmid vector pCM $80 \mathrm{Km}$-hcjb, the resulting transformant showed slower

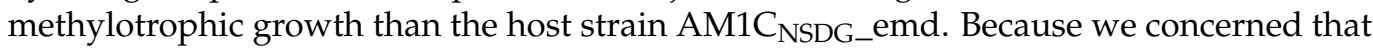
activities of the heterologous enzymes competing with the EMC pathway were too high, another vector was constructed by replacing $P_{m x a F}$ with a putative promoter region of phaA (Mex_1p3700) expecting moderate expression of the genes. However, contrary to expectation, the growth of the strain harboring the resulting vector pCM80PphaA-hcjb on methanol was further impaired in comparison with the strain harboring pCM80Km-hcjb.

\subsection{PHA Production by the Engineered Strains of M. extorquens}

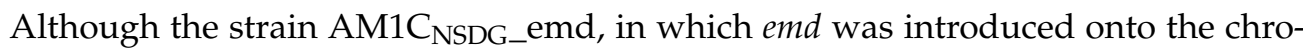
mosome, showed poor growth at $72 \mathrm{~h}$ on methanol under the metal-deficient condition $\left(\mathrm{EDTA}^{+}\right)($Table 2$)$, the dry cell weight of this strain harboring the empty vector pCM80Km reached comparable level with that of $\mathrm{AM} 1 \mathrm{C}_{\mathrm{NSDG}} / \mathrm{pCM} 80 \mathrm{Km}$ after a prolonged $96 \mathrm{~h}$ cultivation (Figure 2). Therefore, PHA synthesis by the engineered strains was evaluated after

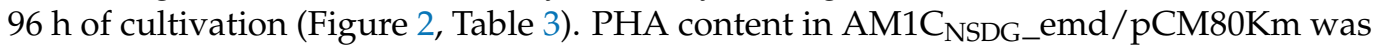
slightly higher than that in $\mathrm{AM} 1 \mathrm{C}_{\mathrm{NSDG}} / \mathrm{pCM} 80 \mathrm{Km}$, and the PHA composition was not changed by introducing Emd $_{M m}$. The strains with the enhanced RBO pathway,

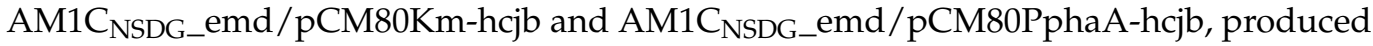
PHAs consisted of 4.1-4.2 mol\% 3HV and 0.9-1.1 mol\% 3HHx composition, which were

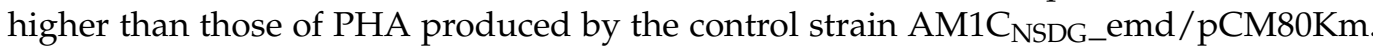
These RBO-enhanced strains showed PHA contents as high as $40 \mathrm{wt} \%$, whereas the PHA production was lower than that by the control strain due to the lower cell growth (dry cell weight). 


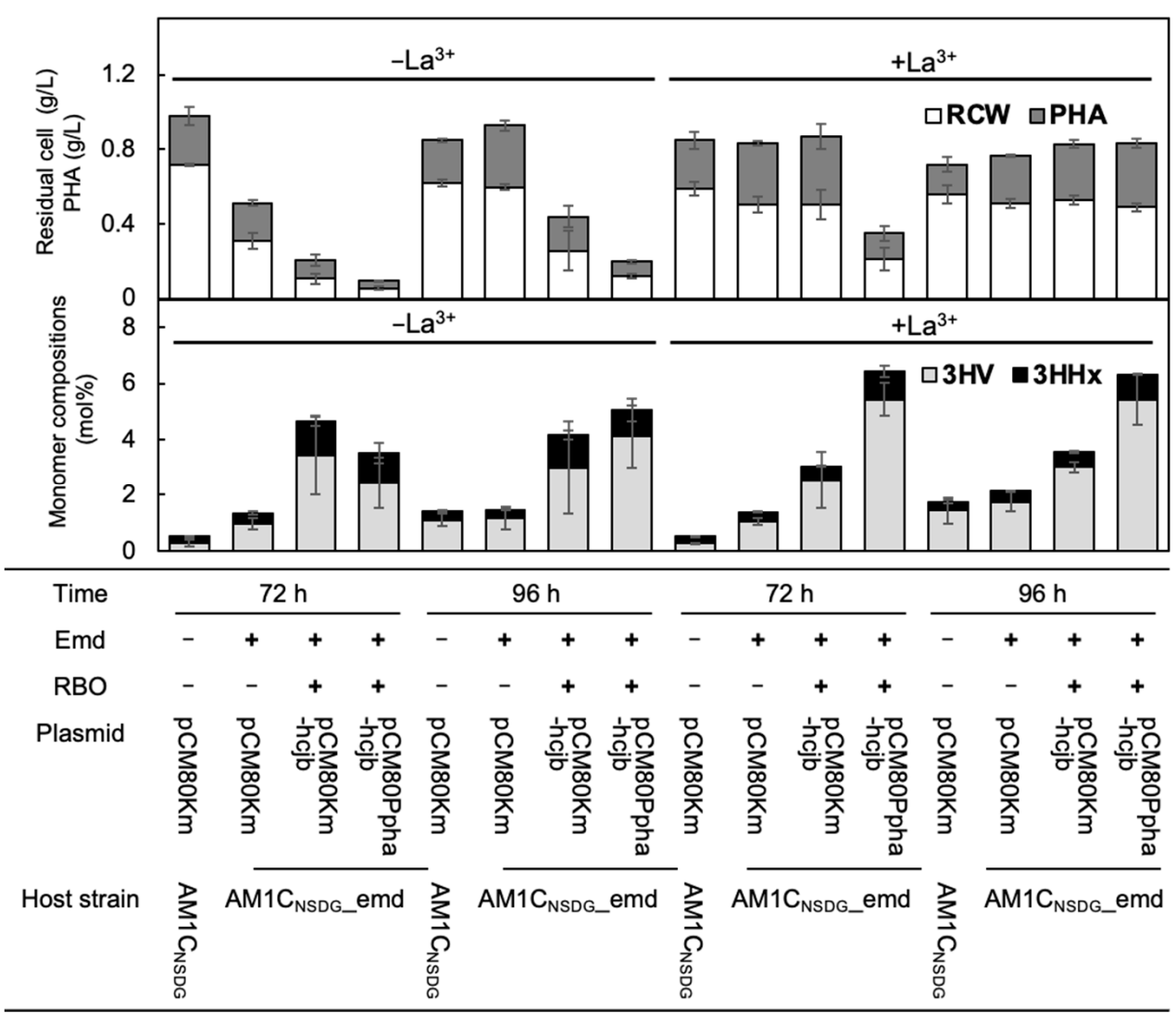

Figure 2. $\mathrm{P}(3 \mathrm{HB}-\mathrm{co}-3 \mathrm{HV}-\mathrm{co}-3 \mathrm{HHx})$ biosynthesis from methanol by engineered strains of $\mathrm{M}$. extorquens in the absence or presence of $\mathrm{La}^{3+}$. The cells were grown in $100 \mathrm{~mL}$ hypho medium containing $0.5 \%(v / v)$ methanol and trace element solution with EDTA for $72 \mathrm{~h}$ or $96 \mathrm{~h} . \quad n=4$ ( $n=2$ for $\mathrm{AM} 1_{\mathrm{NSDG}} / \mathrm{pCM} 80 \mathrm{Km}(72 \mathrm{~h})$ ); error bars represent standard deviations.

Table 3. Effect of lanthanide on $\mathrm{P}(3 \mathrm{HB}-\mathrm{co}-3 \mathrm{HV}-\mathrm{co}-3 \mathrm{HHx})$ biosynthesis by $\mathrm{M}$. extorquens recombinant strains from methanol.

\begin{tabular}{|c|c|c|c|c|c|c|c|c|c|}
\hline \multirow{2}{*}{ Strain } & \multirow{2}{*}{ Plasmid } & \multirow{2}{*}{ La } & \multirow{2}{*}{$\begin{array}{c}\text { Dry cell } \\
\text { Weight } \\
(\mathrm{g} / \mathrm{L})\end{array}$} & \multirow{2}{*}{$\begin{array}{c}\text { PHA } \\
\text { Content } \\
(w t \%)\end{array}$} & \multirow{2}{*}{$\begin{array}{l}\text { PHA } \\
\text { (g/L) }\end{array}$} & \multirow{2}{*}{$\begin{array}{l}\text { Residual Cell } \\
\text { Weight } \\
\text { (g/L) }\end{array}$} & \multicolumn{3}{|c|}{$\begin{array}{c}\text { Monomer Composition } \\
(\mathrm{mol} \%)\end{array}$} \\
\hline & & & & & & & $3 \mathrm{HB}$ & $3 \mathrm{HV}$ & $3 H H x$ \\
\hline \multirow[t]{2}{*}{$\mathrm{AM} 1 \mathrm{C}_{\mathrm{NSDG}}$} & $\mathrm{pCM} 80 \mathrm{Km}$ & & $0.85 \pm 0.02$ & $27.1 \pm 1.2$ & $0.23 \pm 0.01$ & $0.62 \pm 0.02$ & $98.6 \pm 0.3$ & $1.09 \pm 0.22$ & $0.31 \pm 0.04$ \\
\hline & pCM80Km-emd & & $0.07 \pm 0.01$ & $27.4 \pm 1.7$ & $0.02 \pm 0.00$ & $0.05 \pm 0.01$ & $98.1 \pm 0.3$ & $0.97 \pm 0.21$ & $0.89 \pm 0.11$ \\
\hline \multirow{3}{*}{$\mathrm{AM}_{1 C_{\text {NSDG_emd }}}$} & pCM80Km & - & $0.93 \pm 0.04$ & $35.5 \pm 1.8$ & $0.33 \pm 0.03$ & $0.59 \pm 0.02$ & $98.5 \pm 0.4$ & $1.15 \pm 0.40$ & $0.32 \pm 0.03$ \\
\hline & pCM80Km-hcjb & & $0.44 \pm 0.16$ & $42.3 \pm 2.8$ & $0.18 \pm 0.05$ & $0.26 \pm 0.10$ & $95.8 \pm 1.7$ & $3.00 \pm 1.67$ & $1.17 \pm 0.15$ \\
\hline & pCM80PphaA-hcjb & & $0.20 \pm 0.02$ & $39.7 \pm 2.1$ & $0.08 \pm 0.01$ & $0.12 \pm 0.01$ & $95.0 \pm 1.4$ & $4.11 \pm 1.12$ & $0.94 \pm 0.40$ \\
\hline \multirow[t]{2}{*}{$\mathrm{AM} 1 C_{\mathrm{NSDG}}$} & $\mathrm{pCM} 80 \mathrm{Km}$ & & $0.72 \pm 0.09$ & $22.2 \pm 2.5$ & $0.16 \pm 0.04$ & $0.56 \pm 0.05$ & $98.3 \pm 0.5$ & $1.43 \pm 0.48$ & $0.32 \pm 0.05$ \\
\hline & pCM80Km-emd & & $0.61 \pm 0.06$ & $27.2 \pm 0.8$ & $0.17 \pm 0.02$ & $0.44 \pm 0.04$ & $97.9 \pm 0.1$ & $1.55 \pm 0.04$ & $0.55 \pm 0.04$ \\
\hline \multirow{3}{*}{ AM1C NSDG_emd $_{\text {na }}$} & pCM80Km & + & $0.77 \pm 0.02$ & $33.6 \pm 1.6$ & $0.26 \pm 0.01$ & $0.51 \pm 0.02$ & $97.9 \pm 0.3$ & $1.75 \pm 0.34$ & $0.37 \pm 0.02$ \\
\hline & pCM80Km-hcjb & & $0.83 \pm 0.02$ & $36.2 \pm 2.3$ & $0.30 \pm 0.02$ & $0.53 \pm 0.02$ & $96.4 \pm 0.2$ & $3.02 \pm 0.17$ & $0.55 \pm 0.04$ \\
\hline & pCM80PphaA-hcjb & & $0.83 \pm 0.01$ & $41.3 \pm 2.6$ & $0.34 \pm 0.02$ & $0.49 \pm 0.02$ & $93.7 \pm 1.0$ & $5.42 \pm 0.89$ & $0.90 \pm 0.12$ \\
\hline
\end{tabular}

\subsection{Both Methylotrophic Growth and PHA Production Were Restored by Addition of $\mathrm{La}^{3+}$}

The enhancement of the RBO pathway in M. extorquens resulted in impaired growth on methanol (Figure 3A). The determination of residual methanol concentration in the media indicated that approximately $70 \%$ of the initial methanol remained even after $96 \mathrm{~h}$ cultivation of AM1C NSDG_emd/pCM80PphaA-hcjb showing the lowest methylotrophic growth

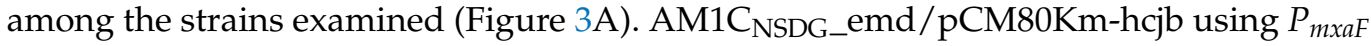
for expression of the heterologous genes showed slow growth and methanol consumption as well (Figure 3A). 


\section{(A) without $\mathrm{La}^{3+}$}
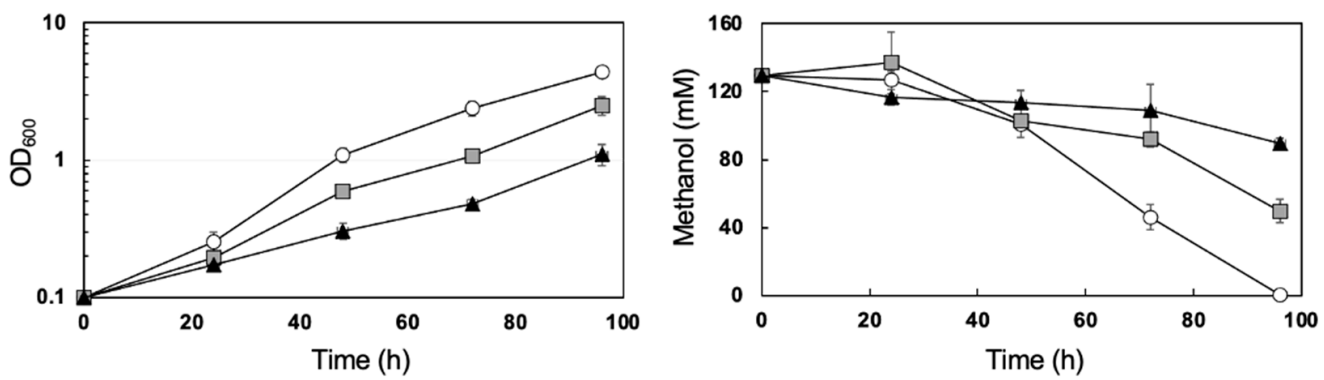

(B) with $\mathrm{La}^{3+}$
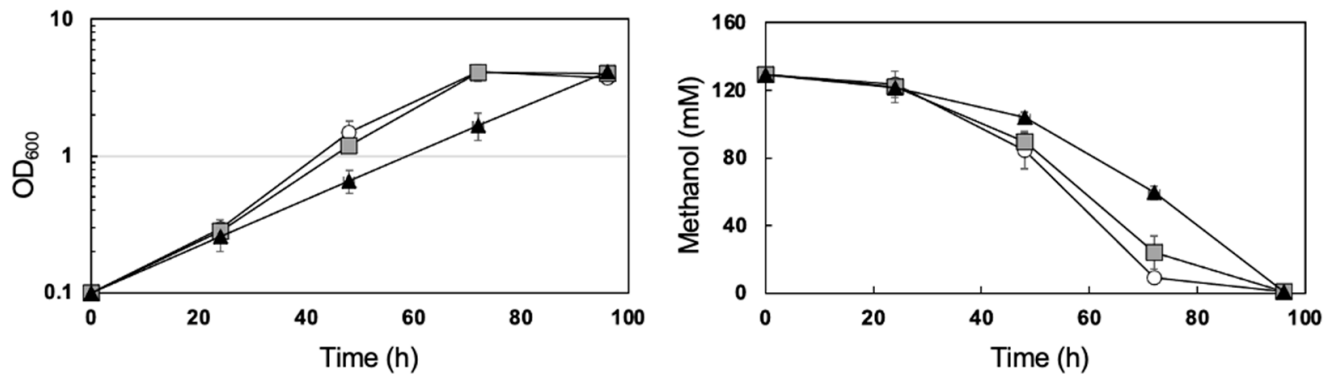

Figure 3. Time courses of growth of and methanol consumption by engineered strains of M. extorquens. The cells were grown in $100 \mathrm{~mL}$ hypho medium containing $0.5 \%(v / v)$ methanol and trace element solution with EDTA in the absence $(\mathbf{A})$ or presence $(\mathbf{B})$ of $\mathrm{La}^{3+}$. Open circle, AM1C $\mathrm{NSDG}_{\mathbf{N}} \mathrm{emd} / \mathrm{pCM} 80 \mathrm{Km}$;

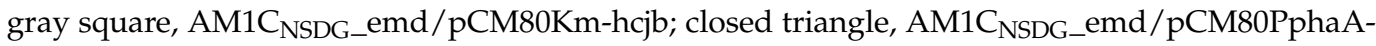
hcjb. $n \geq 3$; error bars represent standard deviations.

Given the much larger metabolic flux of methanol oxidation than $\mathrm{C}_{1}$ assimilation for the conservation of energy and reducing equivalents required for the growth [28], it was assumed that the repression of methanol oxidation may have some relation to the poor methylotrophic growth of the engineered strains. The methanol oxidation is mainly catalyzed by $\mathrm{Ca}^{2+}$-dependent $\mathrm{MDH}(\mathrm{MxaFI})$ in $\mathrm{M}$. extorquens AM1, while recent studies revealed that this methylotroph possesses the second MDH, the lanthanide-dependent XoxF1, and the expression and activity of XoxF1 are induced under the presence of lanthanide $[29,30]$. We thus investigated the effects of lanthanide on the growth of the engineered strains of $M$. extorquens, and interestingly observed that the poor methylotrophic growth and methanol consumption of the RBO-enhanced strains were both restored by the addition of $30 \mathrm{mM} \mathrm{LaCl}_{3}$ into the culture medium (Figure 3B). AM1C $\mathrm{NSDG}_{2}$ emd/pCM80Km and

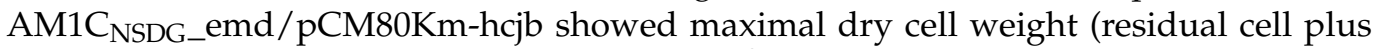
PHA) at $72 \mathrm{~h}$ of cultivation in the presence of $\mathrm{La}^{3+}$ (Figure 2). Notably, both PHA content and compositions of $3 \mathrm{HV}$ and $3 \mathrm{HHx}$ were maintained as high as those in the absence of $\mathrm{La}^{3+}$ (Figure 2, Table 3). It was initially thought that the reduced activity of MxaFI in the engineered strains might be compensated by the induction of XoxF1 in the presence of $\mathrm{La}^{3+}$.

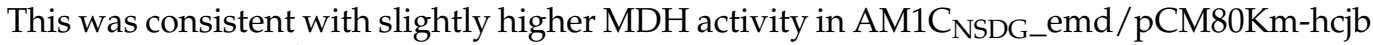
cultivated with $\mathrm{La}^{3+}\left(274 \mathrm{mU} / \mathrm{mg}\right.$ protein) than that in the absence of $\mathrm{La}^{3+}(173 \mathrm{mU} / \mathrm{mg}$

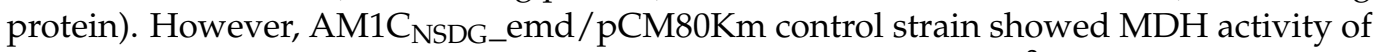
197-234 mU/mg protein regardless of the presence or absence of $\mathrm{La}^{3+}$. It would be feasible that the change of MDH activity in the RBO-enhanced strain by addition of $\mathrm{La}^{3+}$ was not related to the restoration of methylotrophic growth.

\section{Discussion}

The EMC pathway, specific and essential for methylotrophy of M. extorquens and the related methylotrophs, is an attractive pathway for the production of value-added com- 
pounds from methanol because this pathway contains CoA-thioester intermediates with various structures. We have previously found that propionyl/butyryl-CoA intermediates in the EMC pathway were the potential precursors of $\mathrm{P}(3 \mathrm{HB}-\mathrm{co}-3 \mathrm{HV}-\mathrm{co}-3 \mathrm{HHx})$ terpolymer in M. extorquens under $\mathrm{Co}^{2+}$-deficient condition [7]. The $\mathrm{Co}^{2+}$-dependency was thought to be attributed to the activity levels of the two $\mathrm{B}_{12}$-dependent mutases (ethylmalonyl-CoA mutase and methylmalonyl-CoA mutase) in the EMC pathway, responsible for the intracellular concentration of propionyl/butyryl-CoAs. In this study, $\mathrm{Emd}_{M m}$ was introduced into M. extorquens to increase the availability of propionyl/butyryl-CoAs for PHA synthesis through converting methylmalonyl/ethymalonyl-CoAs back to the short-chain acyl-CoAs. However, the expression of $e m d_{M m}$ resulted in growth inhibition on methanol, which was agreed with reduced flux of the EMC pathway weakened by the $\mathrm{Emd}_{M m}$-mediated backward reactions. This growth inhibition was restored by using an EDTA-free trace element solution for the cultivation, probably due to compensation by activation of the two mutases under the high $\mathrm{Co}^{2+}$ concentration. These results again demonstrated the strong association of the EMC pathway with the methylotrophic growth of $M$. extorquens. Considering the 20-times higher catalytic efficiency $\left(k_{\text {cat }} / K_{\mathrm{m}}\right)$ of $\mathrm{Emd}_{M m}$ toward ethylmalonyl-CoA than that to methylmalonyl-CoA, ethylmalonyl-CoA mutase may play a significant role in the methylotrophic growth.

Unfortunately, the introduction of $\mathrm{Emd}_{M m}$ into $M$. extorquens $\mathrm{AM} 1 \mathrm{C}_{\mathrm{NSDG}}$ gave almost no effect on PHA composition despite the function of $\mathrm{PhaC}_{\mathrm{NSDG}}$ and potentially larger pool of propionyl/butyryl-CoAs in the weakened EMC pathway. As it was supposed that the native pathway for conversion of propionyl/butyryl-CoAs to (R)-3HA-CoAs did not work well in $M$. extorquens, further modification was conducted to enhance RBO pathway. In the last decade, RBO pathway has been applied for elongation of acetyl-CoA to higher alcohols, aldehydes, monocarboxylic acids, and so on [31]. Here, four enzymes involved in RBO (BktB, Had, Crt2) and subsequent formation of (R)-3HA-CoAs from 2-enoyl-CoAs (PhaJ4a), which are all derived from and applied in R. eutropha [9], were introduced into $M$. extorquens. The resulting strain $\mathrm{AM}_{\mathrm{NSDG}} / \mathrm{pCM} 80 \mathrm{Km}$-hcjb produced the PHA terpolymer with about a 3-times higher composition of $3 \mathrm{HV}$ and $3 \mathrm{HHx}$ units from methanol when compared with that produced by $\mathrm{AM}_{1} \mathrm{C}_{\mathrm{NSDG}} / \mathrm{pCM} 80 \mathrm{Km}$. In general, copolymerization of $3 \mathrm{HB}$ and other hydroxyalkanoate unit tends to improve the hard and brittle properties of $\mathrm{P}(3 \mathrm{HB})$ homopolymer. In the case of $\mathrm{P}(3 \mathrm{HB}-\mathrm{co}-3 \mathrm{HHx})$, increase in the $3 \mathrm{HHx}$ fraction from 0 to $10 \%$ elevated elongation to break from 5 to $400 \%$ accompanied with a decrease in crystallinity [32]. Another study reported that only $1.5 \mathrm{~mol} \%$ of $3 \mathrm{HHx}$ unit in the copolymer chain markedly decreased the melting temperature from $175^{\circ} \mathrm{C}$ to $150{ }^{\circ} \mathrm{C}$ [33]. Such effect of the copolymerization is not very significant when the second unit is $3 \mathrm{HV}$, because $3 \mathrm{HV}$ is co-crystallized with $3 \mathrm{HB}$, thus elongation to break of $\mathrm{P}(3 \mathrm{HB}-\mathrm{co}-20 \mathrm{~mol} \% 3 \mathrm{HV})$ was only $50 \%$ [32]. Interestingly, the co-crystallization of $3 \mathrm{HB}$ and $3 \mathrm{HV}$ seemed to be prevented by further co-polymerization with $3 \mathrm{HHx}$ [34]. The terpolymers produced by the engineered M. extorquens strains from methanol is expected to exhibit higher flexibility than $\mathrm{P}(3 \mathrm{HB})$ homopolymer, despite the low composition of $\sim 4 \mathrm{~mol} \% 3 \mathrm{HV}$ and $\sim 1 \mathrm{~mol} \% 3 \mathrm{HHx}$. Further engineering of the strains for the synthesis of PHAs with higher $\mathrm{C}_{5} / \mathrm{C}_{6}$ composition and characterization of the polymer will be an important issue to be investigated.

The high 3HV and 3HHx monomer composition in PHA synthesized by the RBOenhanced strains was consistent with channeling of more propionyl/butyryl-CoA intermediates from the EMC pathway to PHA synthesis. Meanwhile, the enhancement of the RBO pathway accompanied severe impairment in the methylotrophic growth under the $\mathrm{Co}^{2+}$-deficient condition, and moreover, the reduction of methanol consumption was observed. These trends were common between the strains using different promoter $\left(P_{\text {mxaF }}\right.$ or $P_{\text {phaA }}$ ) for expression of the RBO pathway genes. The reduction of the overall methanol consumption by the RBO-enhanced strains was thought to be a result of the lower cell concentration in the culture medium. Here we noticed that the cellular methanol consumption by the RBO-enhanced strains were higher during the early growth phase $(0-48 \mathrm{~h})$ when compared to that by AM1C $\mathrm{NSDG}_{-}$emd harboring the pCM80Km empty vector (Figure $4 \mathrm{~A}$ ). 
Namely, the cell yields of the RBO-enhanced strains to methanol were decreased in this term (Figure $4 \mathrm{~B}$ ). Metabolomics analysis of $M$. extorquens revealed that only $16 \%$ of the consumed methanol was assimilated via $\mathrm{H}_{4} \mathrm{~F}$-dependent $\mathrm{C}_{1}$ transfer and the remaining $86 \%$ was completely oxidized to $\mathrm{CO}_{2}$ for energy conservation [28]. Considering the present observation that the RBO-enhanced strain showed no significant decrease in MDH activity, it implies that the reduction of the EMC pathway flux caused by the enhancement of RBO pathway did not significantly affect the methanol catabolism. Impairment of cell growth by the reduction of the EMC pathway lowered cell yield but only at the early phase.

(A) Methanol consumption

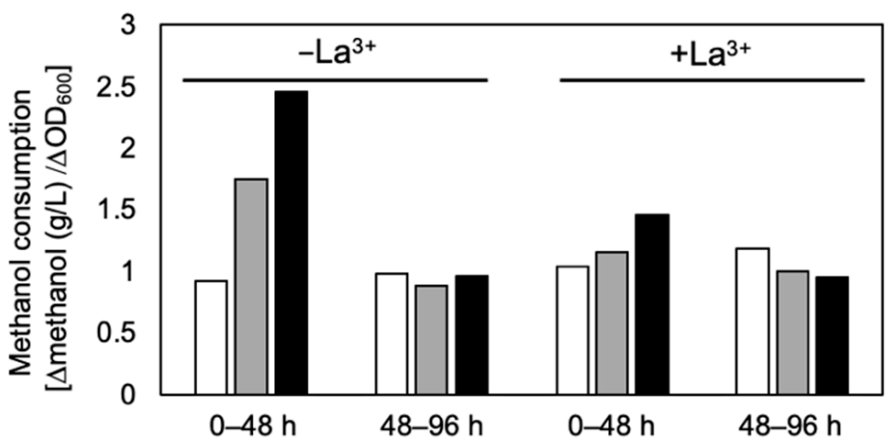

(B) Cell yield

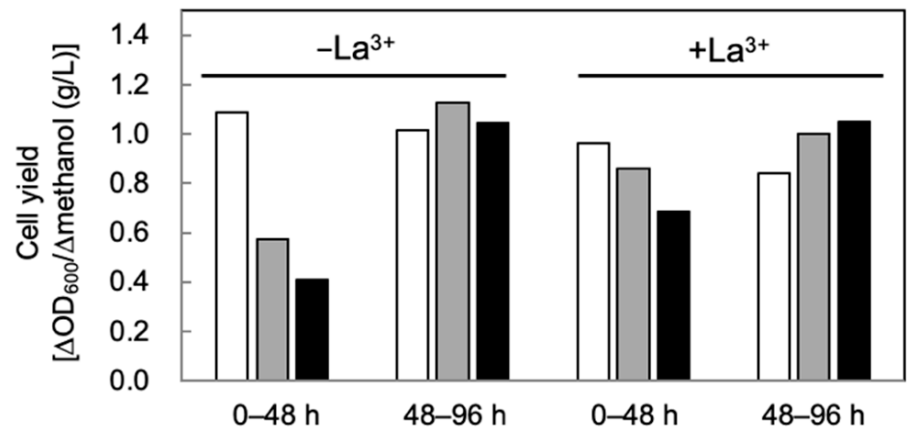

Figure 4. Cellular methanol consumption (A) and cell yield to methanol (B) of engineered strains of $M$. extorquens during initial-mid $(0-48 \mathrm{~h})$ and mid-late $(48-96 \mathrm{~h})$ phases. The cells were grown in $100 \mathrm{~mL}$ hypho medium containing $0.5 \%(v / v)$ methanol and trace element solution with EDTA.

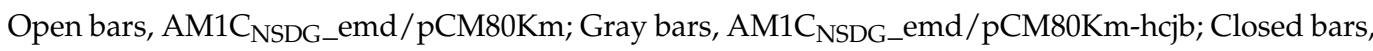

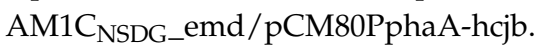

The above results again indicated tradeoff between cell growth and metabolic flux channeled from the EMC pathway, which is a serious problem for the use of the acyl$\mathrm{CoA}$ intermediates for the production of value-added compounds. Recently, regulation of cellular functions by lanthanides (Ln switch) [35] has been recognized to be important for methylotrophy of several methylotrophs and methanotrophs. In this study, we found a possibility that the Ln switch would be useful to overcome the above tradeoff, as the poor cell yields of the engineered $M$. extorquens strains to methanol was restored by the addition of $\mathrm{La}^{3+}$. It should be noted that the higher $3 \mathrm{HV}$ and $3 \mathrm{HHx}$ compositions in PHA synthesized on methanol were maintained during the growth restored by $\mathrm{La}^{3+}$ (Figure 2), unlike the growth restoration by the high concentration of $\mathrm{Co}^{2+}$ accompanied with a decrease in the $3 \mathrm{HV} / 3 \mathrm{HHx}$ composition of PHA (Table 2). It was thought that carbon flux of the EMC pathway was increased by the addition of $\mathrm{La}^{3+}$. However, previous transcriptomic analyses of Methylorubrum species demonstrated that expression levels of genes in $\mathrm{C}_{1}$-assimilation pathways including $\mathrm{H}_{4} \mathrm{~F}$-dependent $\mathrm{C}_{1}$ transfer, the serine cycle, and the EMC pathway, were not up-regulated by lanthanide, in contrast to downregulation of $m x a$ and up-regulation of $x o x$ clusters [36,37]. This rose a possibility for some 
regulation of $\mathrm{C}_{1}$-assimilation pathways by $\mathrm{La}^{3+}$ other than transcriptional induction, such as protein-level activation of some key enzymes in the assimilation pathways. Alternatively, transcriptional behavior to $\mathrm{La}^{3+}$ may be altered when the EMC pathway was modified. Further efforts should be made to understand the detailed mechanism and role of Ln switch in $M$. extorquens. We here achieved flask-scale methylotrophic growth of $M$. extorquens up to $0.8 \mathrm{~g} / \mathrm{L}$ dry cells containing $41.5 \mathrm{wt} \% \mathrm{P}(3 \mathrm{HB}-\mathrm{co}-5.4 \mathrm{~mol} \% 3 \mathrm{HV}-\mathrm{co}-0.9 \mathrm{~mol} \% 3 \mathrm{HHx}$ ) under $\mathrm{La}^{3+}$ - adding condition. A previous studies have demonstrated high-cell-density cultivation of $M$. extorquens on methanol (114-132 g-dry cells/L) by fed-batch strategy [38,39]. The fed-batch cultivation of the engineered strains in the presence of $\mathrm{La}^{3+}$ will allow the efficient production of PHA terpolymers from methanol. Taken together, the results of this study suggested that the response of methylotrophic bacteria to lanthanides would be beneficial for the application of the EMC pathway for bioproduction.

Supplementary Materials: The following are available online at https: / www.mdpi.com/article/ 10.3390/microorganisms10010184/s1, Table S1: The sequences of primers used in this study.

Author Contributions: I.O. designed the study. I.O., G.U. and R.K. engineered the strains, cultivated, and analyzed the engineered strains. I.O. interpreted the data and wrote the original draft. I.O and T.F. reviewed the manuscript. T.F. supervised the work. All authors have read and agreed to the published version of the manuscript.

Funding: This research was supported in part by CREST (JPMJCR15P2 to YS) from Japan Science and Technology Agency and JSPS KAKENHI Grant Number 21H02099.

Institutional Review Board Statement: Not applicable.

Informed Consent Statement: Not applicable.

Data Availability Statement: The data presented in this study are available in the article or Supplementary Materials.

Acknowledgments: We would like to thank Tsubasa Hirabayashi toward his efforts to optimize the method for methanol dehydrogenase assay.

Conflicts of Interest: The authors declare no conflict of interest.

\section{References}

1. Borrelle, S.; Rochman, C.M.; Liboiron, M.; Bond, A.; Lusher, A.; Bradshaw, H.; Provencher, J.F. Opinion: Why we need an international agreement on marine plastic pollution. Proc. Natl. Acad. Sci. USA 2017, 114, 9994-9997. [CrossRef]

2. $\quad$ Eriksen, M.; Lebreton, L.C.; Carson, H.S.; Thiel, M.; Moore, C.J.; Borerro, J.C.; Galgani, F.; Ryan, P.G.; Reisser, J. Plastic pollution in the world's oceans: More than 5 trillion plastic pieces weighing over 250,000 tons afloat at sea. PLoS ONE 2014, 9, e111913. [CrossRef] [PubMed]

3. Jambeck, J.R.; Geyer, R.; Wilcox, C.; Siegler, T.R.; Perryman, M.; Andrady, A.; Narayan, R.; Law, K.L. Plastic waste inputs from land into the ocean. Science 2015, 347, 768-771. [CrossRef]

4. Cotton, C.A.; Claassens, N.J.; Vaquerizo, S.B.; Bar-Even, A. Renewable methanol and formate as microbial feedstocks. Curr. Opin. Biotechnol. 2019, 62, 168-180. [CrossRef]

5. Crowther, G.J.; Kosály, G.; Lidstrom, M.E. Formate as the main branch point for methylotrophic metabolism in Methylobacterium extorquens AM1. J. Bacteriol. 2008, 190, 5057-5062. [CrossRef] [PubMed]

6. Ochsner, A.; Sonntag, F.; Buchhaupt, M.; Schrader, J.; Vorholt, J.A. Methylobacterium extorquens: Methylotrophy and biotechnological applications. Appl. Microbiol. Biotechnol. 2014, 99, 517-534. [CrossRef] [PubMed]

7. Orita, I.; Nishikawa, K.; Nakamura, S.; Fukui, T. Biosynthesis of polyhydroxyalkanoate copolymers from methanol by Methylobacterium extorquens AM1 and the engineered strains under cobalt-deficient conditions. Appl. Microbiol. Biotechnol. 2014, 98, 3715-3725. [CrossRef] [PubMed]

8. Insomphun, C.; Xie, H.; Mifune, J.; Kawashima, Y.; Orita, I.; Nakamura, S.; Fukui, T. Improved artificial pathway for biosynthesis of poly(3-hydroxybutyrate-co-3-hydroxyhexanoate) with high $\mathrm{C}_{6}$-monomer composition from fructose in Ralstonia eutropha. Metab. Eng. 2015, 27, 38-45. [CrossRef]

9. Zhang, M.; Kurita, S.; Orita, I.; Nakamura, S.; Fukui, T. Modification of acetoacetyl-CoA reduction step in Ralstonia eutropha for biosynthesis of poly(3-hydroxybutyrate-co-3-hydroxyhexanoate) from structurally unrelated compounds. Microb. Cell Fact. 2019, 18, 147. [CrossRef] 
10. Yang, S.; Sadilek, M.; Synovec, R.E.; Lidstrom, M.E. Liquid chromatography-tandem quadrupole mass spectrometry and comprehensive two-dimensional gas chromatography-time-of-flight mass spectrometry measurement of targeted metabolites of Methylobacterium extorquens AM1 grown on two different carbon sources. J. Chromatogr. A 2009, 1216, 3280-3289. [CrossRef]

11. Hu, B.; Lidstrom, M.E. Metabolic engineering of Methylobacterium extorquens AM1 for 1-butanol production. Biotechnol. Biofuels 2014, 7, 1-10. [CrossRef] [PubMed]

12. Erb, T.J.; Berg, I.A.; Brecht, V.; Muller, M.; Fuchs, G.; Alber, B.E. Synthesis of $\mathrm{C}_{5}$-dicarboxylic acids from $\mathrm{C}_{2}$-units involving crotonyl-CoA carboxylase/reductase: The ethylmalonyl-CoA pathway. Proc. Natl. Acad. Sci. USA 2007, 104, 10631-10636. [CrossRef]

13. Erb, T.J.; Brecht, V.; Fuchs, G.; Muller, M.; Alber, B.E. Carboxylation mechanism and stereochemistry of crotonyl-CoA carboxylase/reductase, a carboxylating enoyl-thioester reductase. Proc. Natl. Acad. Sci. USA 2009, 106, 8871-8876. [CrossRef]

14. Okubo, Y.; Skovran, E.; Guo, X.; Sivam, D.; Lidstrom, M.E. Implementation of Microarrays for Methylobacterium extorquens AM1. OMICS A J. Integr. Biol. 2007, 11, 325-340. [CrossRef]

15. Schäfer, A.; Tauch, A.; Jäger, W.; Kalinowski, J.; Thierbach, G.; Pühler, A. Small mobilizable multi-purpose cloning vectors derived from the Escherichia coli plasmids pK18 and pK19: Selection of defined deletions in the chromosome of Corynebacterium glutamicum. Gene 1994, 145, 69-73. [CrossRef]

16. Marx, C.J.; Lidstrom, M.E. Development of improved versatile broad-host-range vectors for use in methylotrophs and other Gram-negative bacteria. Microbiology 2001, 147, 2065-2075. [CrossRef] [PubMed]

17. Mifune, J.; Nakamura, S.; Fukui, T. Engineering of pha operon on Cupriavidus necator chromosome for efficient biosynthesis of poly(3-hydroxybutyrate-co-3-hydroxyhexanoate) from vegetable oil. Polym. Degrad. Stab. 2010, 95, 1305-1312. [CrossRef]

18. Woodall, C.A. Electroporation of E. coli. Methods Mol. Biol. 2003, 235, 55-69. [PubMed]

19. Kawashima, Y.; Cheng, W.; Mifune, J.; Orita, I.; Nakamura, S.; Fukui, T. Characterization and functional analyses of R-specific enoyl coenzyme A hydratases in polyhydroxyalkanoate-producing Ralstonia eutropha. Appl. Environ. Microbiol. 2011, 78, 493-502. [CrossRef]

20. Kato, M.; Bao, H.J.; Kang, C.K.; Fukui, T.; Doi, Y. Production of a novel copolyester of 3-hydroxybutyric acid and medium chain length 3-hydroxyalkanaic acids by Pseudomonas sp 61-3 from sugars. Appl. Microbiol. Biotechnol. 1996, 45, 363-370. [CrossRef]

21. Fukui, T.; Doi, Y. Cloning and analysis of the poly(3-hydroxybutyrate-co-3-hydroxyhexanoate) biosynthesis genes of Aeromonas caviae. J. Bacteriol. 1997, 179, 4821-4830. [CrossRef]

22. Day, D.J.; Anthony, C. Methanol dehydrogenase from Methylobacterium extorquens AM1. Methods Enzymol. 1990, 188, 210-216. [CrossRef]

23. Tsuge, T.; Watanabe, S.; Shimada, D.; Abe, H.; Doi, Y.; Taguchi, S. Combination of N149S and D171G mutations in Aeromonas caviae polyhydroxyalkanoate synthase and impact on polyhydroxyalkanoate biosynthesis. FEMS Microbiol. Lett. 2007, 277, 217-222 [CrossRef] [PubMed]

24. Linster, C.L.; Noël, G.; Stroobant, V.; Vertommen, D.; Vincent, M.-F.; Bommer, G.; Veiga-Da-Cunha, M.; Van Schaftingen, E. Ethylmalonyl-CoA decarboxylase, a new enzyme involved in metabolite proofreading. J. Biol. Chem. 2011, 286, 42992-43003. [CrossRef]

25. Šmejkalová, H.; Erb, T.J.; Fuchs, G. Methanol assimilation in Methylobacterium extorquens AM1: demonstration of all enzymes and their regulation. PLoS ONE 2010, 5, e13001. [CrossRef] [PubMed]

26. Sonntag, F.; Muller, J.E.; Kiefer, P.; Vorholt, J.A.; Schrader, J.; Buchhaupt, M. High-level production of ethylmalonyl-CoA pathwayderived dicarboxylic acids by Methylobacterium extorquens under cobalt-deficient conditions and by polyhydroxybutyrate negative strains. Appl. Microbiol. Biotechnol. 2015, 99, 3407-3419. [CrossRef]

27. Segawa, M.; Wen, C.; Orita, I.; Nakamura, S.; Fukui, T. Two NADH-dependent (S)-3-hydroxyacyl-CoA dehydrogenases from polyhydroxyalkanoate-producing Ralstonia eutropha. J. Biosci. Bioeng. 2019, 127, 294-300. [CrossRef]

28. Peyraud, R.; Schneider, K.; Kiefer, P.; Massou, S.; Vorholt, J.A.; Portais, J.C. Genome-scale reconstruction and system level investigation of the metabolic network of Methylobacterium extorquens AM1. BMC Syst. Biol. 2011, 5, 189. [CrossRef]

29. Nakagawa, T.; Mitsui, R.; Tani, A.; Sasa, K.; Tashiro, S.; Iwama, T.; Hayakawa, T.; Kawai, K. A Catalytic Role of XoxF1 as $\mathrm{La}^{3+}$-dependent methanol dehydrogenase in Methylobacterium extorquens strain AM1. PLoS ONE 2012, 7, e50480. [CrossRef] [PubMed]

30. Vu, H.; Subuyuj, G.A.; Vijayakumar, S.; Good, N.M.; Martinez-Gomez, N.C.; Skovran, E. Lanthanide-dependent regulation of methanol oxidation systems in Methylobacterium extorquens AM1 and their contribution to methanol growth. J. Bacteriol. 2016, 198, 1250-1259. [CrossRef]

31. Kallscheuer, N.; Polen, T.; Bott, M.; Marienhagen, J. Reversal of $\beta$-oxidative pathways for the microbial production of chemicals and polymer building blocks. Metab. Eng. 2017, 42, 33-42. [CrossRef]

32. Tsuge, T. Metabolic improvements and use of inexpensive carbon sources in microbial production of polyhydroxyalkanoates. J. Biosci. Bioeng. 2002, 94, 579-584. [CrossRef]

33. Fukui, T.; Abe, A.H.; Doi, Y. Engineering of Ralstonia eutropha for Production of Poly(3-hydroxybutyrate-co-3-hydroxyhexanoate) from Fructose and Solid-State Properties of the Copolymer. Biomacromolecules 2002, 3, 618-624. [CrossRef]

34. Bhubalan, K.; Lee, W.H.; Loo, J.C.Y.; Yamamoto, T.; Tsuge, T.; Doi, Y.; Sudesh, K. Controlled biosynthesis and characterization of poly(3-hydroxybutyrate-co-3-hydroxyvalerate-co-3-hydroxyhexanoate) from mixtures of palm kernel oil and 3HV-precursors. Polym. Degrad. Stab. 2008, 93, 17-23. [CrossRef] 
35. Pastawan, V.; Suganuma, S.; Mizuno, K.; Wang, L.; Tani, A.; Mitsui, R.; Nakamura, K.; Shimada, M.; Hayakawa, T.; Fitriyanto, N.A.; et al. Regulation of lanthanide-dependent methanol oxidation pathway in the legume symbiotic nitrogen-fixing Bacterium bradyrhizobium sp. strain Ce-3. J. Biosci. Bioeng. 2020, 130, 582-587. [CrossRef] [PubMed]

36. Masuda, S.; Suzuki, Y.; Fujitani, Y.; Mitsui, R.; Nakagawa, T.; Shintani, M.; Tani, A. Lanthanide-dependent regulation of methylotrophy in Methylobacterium aquaticum strain 22A. Msphere 2018, 3, e00462-17. [CrossRef]

37. Good, N.M.; Moore, R.S.; Suriano, C.J.; Martinez-Gomez, N.C. Contrasting in vitro and in vivo methanol oxidation activities of lanthanide-dependent alcohol dehydrogenases XoxF1 and ExaF from Methylobacterium extorquens AM1. Sci. Rep. 2019, 9, 1-12. [CrossRef]

38. Bourque, D.; Pomerleau, Y.; Groleau, D. High cell density production of poly- $\beta$-hydroxybutyrate (PHB) from methanol by Methylobacterium extorquens: Production of high-molecular-mass PHB. Appl. Microbiol. Biotechnol. 1995, 44, 367-376. [CrossRef]

39. Mokhtari-Hosseini, Z.B.; Vasheghani-Farahani, E.; Shojaosadati, S.A.; Karimzadeh, R.; Heidarzadeh-Vazifekhoran, A. Effect of feed composition on PHB production from methanol by HCDC of Methylobacterium extorquens (DSMZ 1340). J. Chem. Technol. Biotechnol. 2009, 84, 1136-1139. [CrossRef] 